\title{
AVAUIAÇÃO DA APRENDIZAGEM: UM PROJETO VIVIDO
}

Regina Célia Brenner Kasai*

A avaliação, apesar de proclamada como parte do processo ensino aprendizagem, mereceu sempre, no cotidiano das práticas pedagógicas, um lugar de destaque na preocupação e no imaginário de alunos e professores.

O fato de alunos universitários viverem em "busca da nota" é um fato histórico. Revela o lugar que a prova e a nota ocupam durante a vida escolar. Vestibulinhos, semana de provas, divulgação em edital das notas, boletins com notas azuis e vermelhas, todos tivemos estas experiências. Mais que qualquer discurso, estes fatos mostravam, desde muito cedo, o que é importante fazer na escola para ser bom aluno. Tirar boas notas! Não é a toa o verbo que se emprega. Tirar, arrancar, extrair, fazer sair algo antes depositado, contido e agora posto à mostra, revelado.

Tirar boas notas! Qual o objetivo que se busca? O que isto significa? O que já se denunciou exaustivamente: a avaliação, preocupada com o produto do ensino, recolhe sinais da "qualidade" desse produto. Como o foco não é o aprender, basta um resultado colhido em um único momento e com o mesmo velho procedimento - a prova, considerada suficiente para julgar o aluno, ou melhor, sua capacidade de memorização, reprodução e aplicação do conhecimento transmitido.

A avaliação, assim conduzida, serve ao avaliador em sua função de apreciar e medir. Medir o que se aprendeu e apreciar o valor deste aprendizado e o valor do próprio aluno, como observa HADJI (1994, p. 77), ao esclarecer que o avaliador pode assumir três lugares distintos: o do especialista (que mede), o do juiz (que aprecia) e o do filósofo (que compreende e interpreta).

Um único resultado colhido num único momento, basta também, na

* Mestranda em Educação - Professora do Curso de Fonoaudiologia da Pontifícia Universidade Católica do Paraná. 
dinâmica institucional e na burocracia escolar, para julgar o professor. Quantos deixou para recuperação? Quantos reprovou? Quantos conseguiram passar? De novo as palavras denunciam relações e intenções, de novo o poder de avaliar de forma arbitrária e unilateral, o ser e seu trabalho, seu valor e o valor do que produziu. (TRINDADE e WACHOWICZ, 1998; HADJI, 1994)

Não se trata de execrar a prova em si. Trata-se de denunciar uma avaliação que, voltada para si própria, espelha o jogo do "eu finjo que ensino e você finge que aprende" (WERNECK,1993). Fragmento de uma concepção de ensino - aprendizagem tradicional, esta avaliação mantém cativos corpos, emoções e mentes de professores e alunos, eternamente a reproduzir a angústia e o prazer de tal jogo.A prática autoritária da avaliação da aprendizagem, em todos os níveis de ensino, encontra-se atrelada a uma lógica da seleção (PERRENOUD,1999) e é caracterizada por privilegiar o que não se aprendeu, por valorizar a reprodução de informações, por ignorar as diversas formas e o tempo de aprender dos estudantes (WACHOWICZ, 2000; HOFFMANN,1998).

Parte de um processo de ensino - aprendizagem tradicional, que embota a criatividade dos estudantes, mata seu desejo de aprender e transforma o saber em conteúdos a serem assimilados como verdades prontas e acabadas, a avaliação da aprendizagem é fundamentada e determinada, em grande parte, pelas representações sociais que construímos.

Essas representações sobre o que é o aluno, o professor, a avaliação, a relação aluno/professor, são determinadas historicamente e fundamentadas no senso comum..

Desta forma, qualquer mudança na avaliação da aprendizagem só pode ocorrer no dia a dia da sala de aula, no confronto de interesses, nos momentos de negociação, no desafio cotidiano a que se lançam educadores e educadoras, quando conseguem ser reflexivos e críticos de sua prática pedagógica. O desafio torna-se então o de avaliar com rigor e amorosidade (FREIRE, 1998), com qualidade formal e política, DEMO (1987), num processo pautado na lógica da regulação da aprendizagem do aluno (HADJI,1994; PERRENOUD, 1993) e na ética da solidariedade, da inclusão e da liberdade (BOFF,1997; FREIRE,1996, 1998 e ADORNO, 1995).

A mudança na avaliação da aprendizagem só pode ser vivida em seu interior, no porque e para que se avalia, à medida que professores e alunos se encontram como companheiros de aprendizado, como responsáveis pela transformação e/ou construção de representações e de saberes, despidos de preconceitos, de verdades absolutas, de lugares definidos e poderes sacralizados. Há vários caminhos para se chegar à avaliação da aprendizagem coerente com o paradigma inovador de Educação. Porém é certo que a formação continuada dos docentes, conforme assinala BEHRENS (1996), a compreensão de que os protagonistas deste processo são seres com histórias, culturas, valores e tempos de aprender diferentes, o desejo de ensinar e aprender com liberdade 
e amor, a competência profissional e o autoconhecimento, são elementos fundamentais em qualquer um desses caminhos.

A avaliação da aprendizagem não é algo apartado dos demais momentos da vida da sala de aula. Ela ocorre num espaço físico, temporal, relacional, circunstancial e histórico, sendo atravessada por todas as variáveis imagináveis de qualquer processo humano. Deve, portanto, ser transparente e criteriosa e estar a serviço do estudante, a fim de que possa ser uma oportunidade de diálogo e uma possibilidade de leitura da realidade vivenciada por professores e professoras com seus estudantes.

Para que isto ocorra, cabe a cada educador fazer suas escolhas diante dos problemas técnicos da avaliação, de sua utilização social e de suas intenções. Tais escolhas serão determinadas pelo lugar em que o professor se coloca ao avaliar.

Este lugar pode ser o da pessoa que mensura, da que julga ou da que faz uma possível leitura da realidade do processo ensino - aprendizagem que se vivencia, interpretando-a para e com seus alunos. As escolhas devem ser pautadas por critérios os mais transparentes possíveis a todos os envolvidos, consoantes com um projeto político - pedagógico que, além de considerar as particularidades do curso em questão, leve em conta as tendências da educação superior para o século XXI, amplamente discutidas nas conferências nacionais e mundiais sobre o ensino superior, como a ocorrida em outubro de 1998, em Paris, França. ${ }^{2}$

Assim, das variáveis envolvidas na avaliação da aprendizagem a que me parece central e em torno da qual todas as demais se articulam é a que pretende responder à questão: para que avaliar? Em torno dela se articulam as demais decisões. Se a avaliação pretende medir quanto, quando e o quê se reteve, objetiva mais o controle da aprendizagem e dos alunos. Se objetiva julgar o valor da pessoa do aluno e do que aprendeu, mantém como ator principal o professor. Caso sirva para compreender a trama das relações implicadas no processo de aprendizagem, identificar as diferentes formas de aprender de cada estudante e favorecê-las, reconhecer os desafios impostos pelo programa de aprendizagem e as dificuldades de cada aluno em superálos, aí sim, teremos a avaliação como peça de um jogo onde não há vencidos nem vencedores, onde o prêmio é o desejo de saber desperto e a vontade de aprender "saciada".

A avaliação da aprendizagem proposta e vivida durante 0 ano letivo de 1999, com os estudantes do $2^{\circ}$ ano do Curso de Fonoaudiologia da PUCPR que cursavam a disciplina Fonoaudiologia Geral I e II, surgiu da insatisfação da professora diante da abordagem tradicional do processo de ensino -aprendizagem e de sua avaliação, de suas reflexões enquanto aluna do programa de Mestrado em Educação da PUCPR e do desejo de transformar realidades com a ajuda de seus alunos. 
Pretendendo que a aprendizagem fosse um processo de descoberta e construção de saber para a vida, buscou-se um paradigma que ancorasse a avaliação da aprendizagem como instrumento para a autonomia do estudante, o que foi possível ao aliar-se o paradigma do ensino com pesquisa, conforme proposto por Pedro DEMO(1997,1996,1994,1987), à abordagem progressista em educação, conforme Paulo FREIRE (1998a,1998b,1988,1986), sem ignorar toda a contribuição teórica dos autores que se dedicam à avaliação dialógica, democrática, processual, cumulativa e também ao processo de ensinar e aprender de forma significativa, transformadora, com alegria e liberdade. ${ }^{3}$

A avaliação foi conduzida não dissociada do processo de ensino aprendizagem, realizada através de atividades em sala de aula e extra - classes, individual e coletivamente, sem a necessidade de realização de uma prova sequer ao longo do ano. Professora e estudantes compreenderam que diante dos vários procedimentos de avaliação previamente combinados, não havia porque incluir aquele (a prova) que mais aterroriza os estudantes e menos possibilita o exercício da criatividade e produção de saber, da forma como tradicionalmente é feita.

Para que o processo de ensinar a aprender e aprender a ensinar e sua avaliação fosse realmente cooperativo e democrático, todos os temas de estudo, com seu cronograma e com a metodologia de trabalho a ser realizada, assim como os critérios de avaliação, foram apresentados aos estudantes no primeiro encontro do ano letivo, para que fossem discutidos e consensuados.

Passível de negociação sempre que uma modificação de planos (discutida em sala de aula) parecia ser mais proveitosa para a aprendizagem, tal programa de trabalho mostrou ser um instrumento muito útil à professora e seus alunos e alunas, à medida em que permitiu a organização do trabalho pedagógico e do ritual escolar, o qual para MEIRIEU (1998) além de permitir a organização do espaço e do tempo, regular a vida escolar e codificar gestos e palavras, "garante a cada um a possibilidade de implicar-se e de ao mesmo tempo retrair-se" (ibid, p.95)

foram:

Na proposta de avaliação vivenciada, o diferencial posto em ação

- a busca de estratégias que ampliassem o espaço de atuação do aluno na produção do conhecimento envolvendo-o solidaria e criticamente com o processo ensino - aprendizagem;

- a prática pedagógica pautada pelo paradigma inovador aqui apresentado;

- a avaliação a serviço do estudante e não contra ele;

- a circulação da palavra, do afeto, da criatividade;

- a reflexão constante, coletiva e individual, sobre as várias situações vividas no espaço da sala de aula. 
Ao longo do ano letivo de 1999 e início do ano letivo de 2000 atitudes e depoimentos escritos colhidos com os estudantes do $2^{\circ}$ ano do curso de Fonoaudiologia, permitiram a constatação de que lutar por transformações vale a pena. De estudantes passivos, inicialmente assustados e desconfiados de uma avaliação que não privilegia o erro e não utiliza a prova como arma do professor, os alunos e alunas foram se transformando em sujeitos que agem de forma crítica e reflexiva, produzindo artigos, engajando-se em projetos de pesquisa, terapeutas em formação. No decorrer do processo, os estudantes se revelaram resistentes às propostas tradicionais de ensino que, sendo ainda parte da realidade não só do Curso de Fonoaudiologia da PUCPR, mas de muitos outros, fornecem espaço para um jogo dissimulado de poder onde mensagens que nunca são ditas, deixam muito claro para o aluno e aluna que "esta professora é aquela que a gente tem que escrever até a vírgula" ou que "não adianta argumentar, tem que ser do jeito dele".

Diante do poder que o professor ou professora faz questão de deter (e não há melhor arma para isto que a avaliação da aprendizagem!) não creio ser possível haver autonomia. Enquanto pessoas que ocupam um lugar de educadores acreditarem que sozinhas podem ou devem decidir o que o/a estudante vai aprender, quando, com que estratégias e recursos vão medir tal aprendizagem, não haverá autonomia, não haverá exercício de cidadania e não haverá produção de conhecimento que possa ser considerado como tal.

Ao despir a avaliação do caráter de medida e julgamento, ao eliminar a prova como único procedimento de avaliação (para os estudantes como instrumento de "tortura, terror e pânico"), ao situar a avaliação numa "lógica de ajuda à aprendizagem" (HADJI, 1994), a autonomia, ou quanto menos o posicionamento reflexivo do estudante diante do conhecimento, torna-se realidade, o que pode ser ilustrado pelos depoimentos abaixo:

"Este processo (de avaliação) e o método de dar as aulas são muito melhores que os tradicionais. Porque o aluno sente-se motivado e engajado no processo. Ele faz parte do processo, deve atuar juntamente com o professor para o bom andamento de todo o processo". Estudante 10. Quest.3

"Nesta forma de avaliar, ao meu ver, aprende-se mais pois, não é o professor que descarrega a matéria em cima dos alunos para que estes a decorem, mas sim o aluno que vai atrás da matéria, estuda, tira suas conclusões e 0 professor só tira as dúvidas e complementa o que for necessário. Acho que assim está formando um profissional crítico e que vai atrás dos seus objetivos e não um profissional alienado." Estudante 31. Quest. 3

"Gostei do método usado durante o ano letivo, porque antes de tudo fez com que nós alunos pensássemos de forma reflexiva, avaliássemos a situação. Sinceramente em meu caso me faz sentir segura na hora de responder uma questão, porque eu sinto que realmente aprendi. Estudante 13. Quest.3 
Num mundo onde apontar falhas e destacar o fracasso do ser humano em atender às exigências da escola, da família e do mercado de trabalho, é um exercício diário, conduzido com pouquíssima consciência ou com estéril prazer, por professores e professoras, pais e mães, patrões, mídia impressa e falada, uma proposta de avaliação que resgata a confiança do aluno e da aluna em si próprios e em sua capacidade de aprender, que desperta a curiosidade , que valoriza todo o percurso de produção do conhecimento e não apenas os resultados medidos através de um ou dois instrumentos de avaliação, pode e deve ser generalizada para os diversos cursos da Educação Superior.

Para isto, além de um educador e educadora reflexivos e críticos, engajados numa pedagogia inovadora e libertadora, algumas condições serão necessárias:

1. Um programa de aprendizagem com carga horária de no mínimo três horas/aula em seqüência, para que boa parte das atividades possam ser feitas e concluídas em sala de aula.

2. Acervo da biblioteca rico em títulos e em quantidade suficiente para pesquisa e consulta do número de alunos matriculados no curso.

3. Disponibilidade de tempo do educador ou da educadora despendido fora de sala de aula, na leitura e devolutiva de todos os trabalhos produzidos pelos estudantes.

4. Considerar as horas de estudo e trabalho dos estudantes, a fim de não sobrecarregá-los com atividades que não poderão cumprir por falta de tempo.

5. Turmas com menor número de alunos, pois por em prática tal proposta com mais de uma turma com 60 alunos, é consideravelmente desgastante para o professor e a professora, em função do trabalho de leitura, releitura, devolutivas e pesquisa que se deve empreender.

6. Compreender que o processo de adaptação do aluno à nova proposta será gradual, assim como seu engajamento, visto suas experiências escolares anteriores.

7. Um repensar constante da proposta em andamento, com a necessária flexibilidade para alterar datas, dinâmicas, temas de estudo, critérios de avaliação, sempre que o bom senso e o consenso entre os protagonistas do processo ensino - aprendizagem assim o exigir.

8. Considerar que a busca pela autonomia só pode dar-se em um espaço onde se exerça a liberdade e o respeito mútuo. Ao docente, como autoridade em sala de aula, cabe cuidar para que as condições para o aprender existam. Liberdade sem desordem, disciplina e não repressão, respeito pela palavra e silencio do outro, cumprimento dos acordos feitos, afetividade sem permissividade. 
Numa avaliação para a autonomia há planejamento, há organização, há direcionalidade nas ações, mas não há controle e previsibilidade do processo e dos resultados. A flexibilidade substitui a rigidez, a organização metódica (o passo a passo) do ensinar dá lugar à necessidade de aproveitar todas oportunidades para aprender, a intervenção dos alunos que passam a ocupar seu tempo e espaço de perguntar, substitui a hierarquia de conteúdos, a verbalização de suas dificuldades, medos e inseguranças substitui o silêncio paralisante e auto depreciativo diante das provas e testes.

Ao tomar consciência de todos os tempos deste processo de ensinar e aprender (o do professor, o do aluno, o que se usa para estudar, ler, pesquisar, partilhar), penso que a interdisciplinaridade de programas de aprendizagem acabar por ser necessária. Não apenas porque a interdisciplinaridade, ao buscar a unidade do saber, convida ao trabalho coletivo, ao entrelaçamento de temas, ao debate epistemológico, mas também por poupar o/a aluno/a do estudo e avaliação fragmentados, de conteúdos tantas vezes abordados de forma repetitiva e superficial em mais de uma disciplina. Para isto o envolvimento dos professores e seu efetivo engajamento no projeto político pedagógico do curso é de vital importância.

A avaliação da aprendizagem concebida e concretizada como dialógica, emancipadora, democrática, processual e cumulativa, exige liberdade de movimento e de decisão. Ou seja, não pode ser engessada em determinações administrativas rígidas do quando e como avaliar. Dizendo melhor: a avaliação que se coloca na "lógica da aprendizagem", negando-se a ser instrumento de seleção e exclusão só acontece num espaço e tempo construídos por seus protagonistas e só ganha vida se conduzida por educadores e educadoras engajados politicamente, comprometidos eticamente e preparados formalmente para o exercício do ensinar e aprender com seriedade, criticidade e amorosidade. Não se trata apenas de assumirmos práticas de avaliação inovadoras, mas sim de transformarmos realidades e sermos por elas transformados.

\section{Notas Bibliográficas}

1. Ver: Anais da Conferência Mundial sobre o Ensino Superior: Tendências da Educação Superior para 0 século XXI, trad. GONÇALVES, M. B. UNESCO/CRUB, 1999.

2. Ver: BEHRENS, (1999); CARDOSO, (1995); HADJI (1994), MACHADO (1995); MEIRIEU (1998); PERRENOUD (1999,1993); POZO, (1998) entre outros.

\section{Referências Bibliográficas}

ADORNO, Theodor W. Educação e emancipação. Trad. Wolfgang Leo Maar. Rio de Janeiro, Paz e Terra, 1995. 
BEHRENS, Marilda. O paradigma emergente e a prática pedagógica. Curitiba: Champagnat, 1999.

. Formação continuada dos professores e a prática pedagógica. Curitiba: Champagnat, 1996.

BOFF, Leonardo. A águia e a galinha: uma metáfora da condição humana. 24. ed. Petrópolis, Vozes, 1997.

CARDOSO, Clodoaldo, M. A canção da inteireza. Uma visão holística da educação. São Paulo: Summus, 1995.

DEMO, Pedro. Avaliação qualitativa. São Paulo: Cortez, Autores Associados, 1987.

.Pesquisa e construção de conhecimento: metodologia científica no caminho de Habermas. Rio de Janeiro: Tempo Brasileiro, 1994.

. Pesquisa: princípio científico e educativo. 5. ed. São Paulo: Cortez, Autores Associados, 1997

. Educar pela pesquisa. 2. ed. Campinas: Papirus, Autores associados, 1997.

. Avaliação sob o olhar propedêutico. Campinas: Papirus, 1996.

FREIRE, Paulo. Pedagogia da autonomia. Saberes necessários para a prática

Educativa. 9.ed. São Paulo: Paz e Terra, 1998.(a)

. Pedagogia da Esperança: um reencontro com a pedagogia do oprimido. 5. ed. São Paulo: Paz e Terra, 1998 (b)

. Pedagogia do oprimido.18 ed. Rio de Janeiro: Paz e Terra,1988.

FREIRE, Paulo; SHOR, Ira. Medo e ousadia. O cotidiano do Professor. Rio de Janeiro: Paz e Terra, 1986.

HADJI, Charles. A avaliação, regras do jogo: das intenções aos instrumentos. Portugal: Porto Editora, 1994.

HOFFMANN, Jussara. Pontos e contrapontos: do pensar a o agir em avaliação. Porto Alegre: Mediação, 1998.

MACHADO, Nilson José. Epistemologia e didática. As concepções de conhecimento e inteligência e a prática docente. São Paulo: Cortez, 1995.

MEIRIEU, Philippe. Aprender ... sim, mas como? 7. ed. Porto Alegre : Artes Médicas, 1998 
PERRENOUD, Philippe. Avaliação: da excelência à regulação das aprendizagens - entre duas lógicas. Porto Alegre: Artes Médicas, 1999.

. Não mexam na minha avaliação! Para uma abordagem sistemática da mudança pedagógica. In: ESTRELA, Albano e NÓVOA, Antonio.(org.) Avaliações em educação: novas perspectivas. Porto: Porto editora, 1993.

. Formação inicial dos professores e profissionalização. In Práticas pedagógicas, profissão docente e formação. Perspectivas sociológicas. Lisboa : Don Quixote, 1993

POZO, Juan Ignacio. Teorias cognitivas da aprendizagem. 3. ed. Porto Alegre: Artes Médicas, 1998.

TRINDADE, Zuleika de S.; WACHOWICZ, Lilian, A . A distância entre a teoria e a prática da avaliação da aprendizagem na Educação Superior. In: Resúmenes do Encuen tro por la unidade delos educadoreslatinoamericanos. Cuba, Havana, 1999.

UNESCO/CRUB. Anais da Conferen cia Mundial sobre o Ensino Superior. Tendências de Educação Superior para o Século XXI, Brasília: UNESCO/CRUB, 1999.

WACHOWICZ, Lilian Anna. A dialética da avaliação da aprendizagem, na pedagogia diferenciada. In: CASTANHO, Maria Eugênia e CASTANHO, Sérgio (org.) O que há de novo na Universidade: do projeto pedagógico à prática transformadora . Campinas (SP): Papirus, 2000.

WERNECK, Hamilton. Se você finge que ensina, eu finjo que aprendo. 4 ed. Petrópolis: Vozes, 1993. 